The 5th International Symposium on Robotics in Construction June 6-8, 1988 Tokyo, Japan

\title{
THE COMPUTER CONTROLLED SYSTEM OF DEEP SLURRY WALL CONSTRUCTION
}

\author{
Toshio Nakamura \\ Kozaburo Tsuchiya \\ OHBAYASHI CORPORATION \\ Kubota Bldg., 15-11, \\ Uchikanda 1-chome, Chiyoda-Ku, \\ Tokyo 101, Japan
}

\begin{abstract}
Recently a slurry wall which is continuously excavated in underground should be constructed deeper and wider. For instance the slurry wall of $150 \mathrm{~m}$ deep was constructed last year. It was difficult to keep the precision of the wall without the computer controlled system. This paper presents a new computer controlled system including a multi data transmission system, a remote controlled system of the excavator, an automatic slurry quality controlled system and an expert system to perform good excavation. We also developed a robbot which disconnects a tremi pipe automatically with a sensor to detect the top of the pouring concrete in the slurry wall. The author believes that this system is the first step to the Site Automation.
\end{abstract}

\section{INTRODUCTION}

Last a few years, demands of the big projects of heavy construction such as the underground excavation has been increased. Underground water stopping wall which is called "Slurry wall" was used as temporary wall, but we are planing to use it as permanent wall. Because we can construct more accurate and higher quality underground wall. The condition to construct the good underground wall, is shown as following.

1) An efficient excavator which has enough endurance and power. 
2) Skilled operators, able engineers, good electricians and mechanics.

3) A project manager who has the rich experience.

4) A back up plant to process the slurry from the wall efficiently.

But these conditions are not good enough to construct deeper than $100 \mathrm{~m}$ and wider than $3 \mathrm{~m}$ slurry wall. When the author planed the deepest slurry wall in the world, a total excavation controlled system by computer was adopted. After all the various data from the excavator are taken in the computer and processed, then they are fed back to the operation of the excavator immediately. Consequently we got great success according to our CIC (Computer integrated Construction) system. Following data is the specification of the excavator.

1) Weight; 50ton

2) Length; $13 \mathrm{~m}$

3) Accuracy of excavation ; 1/2000 (minimum)

4) Maximum excavation depth ; 170m

2. THE PROCEDURE OF THE SLURRY WALL CONSTRUCTION

The following is procedure of the slurry wall construction (see Fig 2.)

1) Excavation

2) Insertion of steel rebar armature

3) Placement of concrete

4) Completion of the wall

\section{COMPUTER INTEGRATED CONSTRUCTION}

As the author explained in the INTRODUCTION, the accuracy of excavation is improved by the good balance control of the excavator. This is the most important technics of the slurry wall excavation. Therefore every datum should be transmitted to the control room from the excavator, then the processed data are fed back to the machine immediately and 
accurately. The data from the excavator such as the inclination, the stroke of adjustable plate, the depth, the weight, the hydraulic pressure and others, are transmitted to the computer by MTS (Multiplex - Transmission System).

In the control room, these data are indicated on the control-panel and also displayed on the CRT (photo 3 ) when you see this operation room, you can imagine the operation room of factory automation

The author would like to explain the excavation system which is controlled by the computer more detail. The excavator vertically goes down into the underground wall which are filled up with slurry to maintain the wall condition. This machine is remote-controlled by skilled operators in the control room. This fifty tons heavy excavator is excavating within 0.1 degree inclination. These operation depends on the advanced technology of sensor and computer.

\section{MULTIPLEX TRANSMISSION SYSTEM (MTS)}

The Multiplex Transmission System was developed for the excavator control system. MTS consists of a invertor, a convertor and only one cable which consists of a few coaxial cable instead of the plural multicore cables.

\section{AUTOMATIC MEASUREMENT SYSTEM FOR THE QUALITY OF SLURRY}

Slurry, mainly composed of bentonife or polymer, is used in order to stabilize the trench wall during the excavation and to ensure the quality of the concrete in the wall. This system measure of the quality of the slurry such as density, $\mathrm{PH}$, temperature, etc. automatically, then the slurry is controlled at the most suitable condition. (Photo 4)

\section{ROBOT DISCONNECTS AND REMOVES THE TREMIE PIPE}

THE TOKYO ELECTRIC POWER CO., INC. AND OHBAYASHI CORPORATION have developed the new system consist of the device which detects the top of the pouring concrete in the slurry wall and the robot which disconnects and removes the tremie pipe. (Photo 5, Figure 3) 


\section{CONCLUSION}

The author believes that this CIC system is the entrance to the SA (Site - Automation). In the construction field, if a single automatic machine has been developed independently, it would not reach the SA eventually. Basically, the contractor would like to do the good job financially, safely accurately and fast according to the specification. First of all the general contractors should aim at the establishment of the total construction system, then they should be developing the subsystem such as robot or automatic system steadily. After all the robot which is not incorporated into the construction system, is only toy.

There are many unknown phenomena under the heavy construction, especially underground job. So we have to establish higher construction system, eventually our destination is Site Automation (SA). 


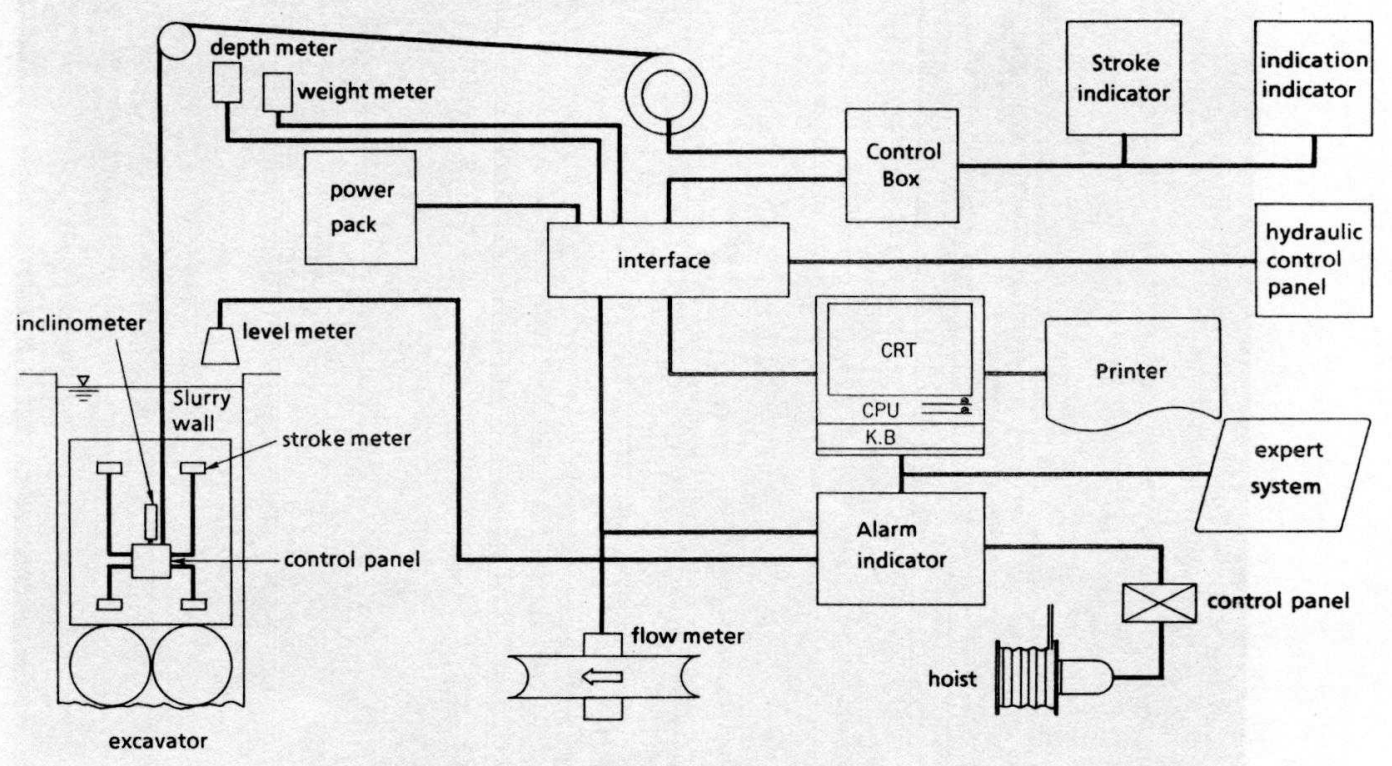

Figure 1. Computer Integrated Construction system of the slurry wall.

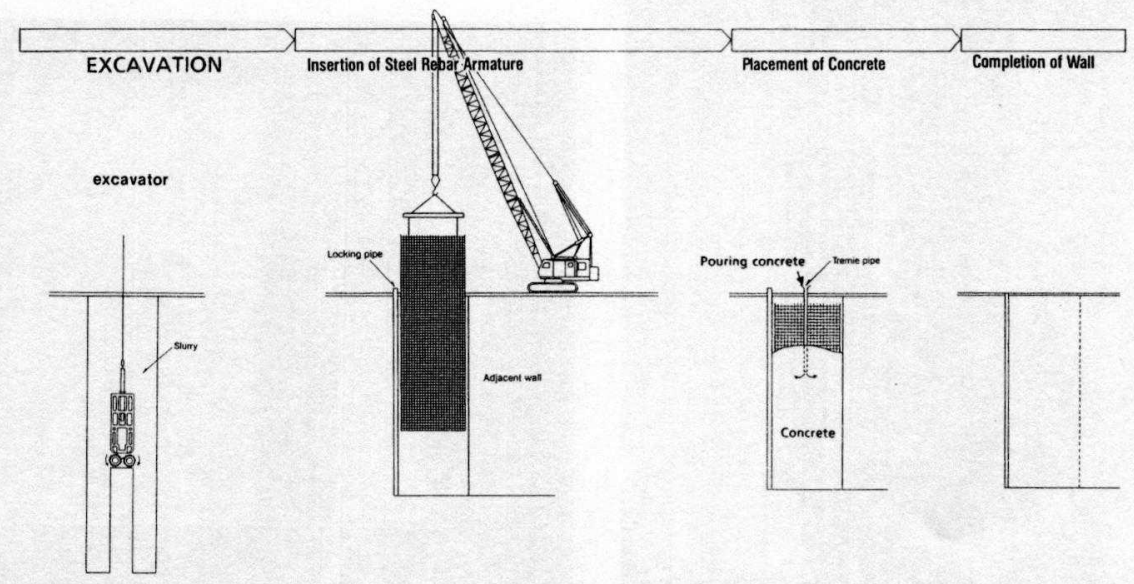

Figure 2. The construction procedure of the slurry wall 


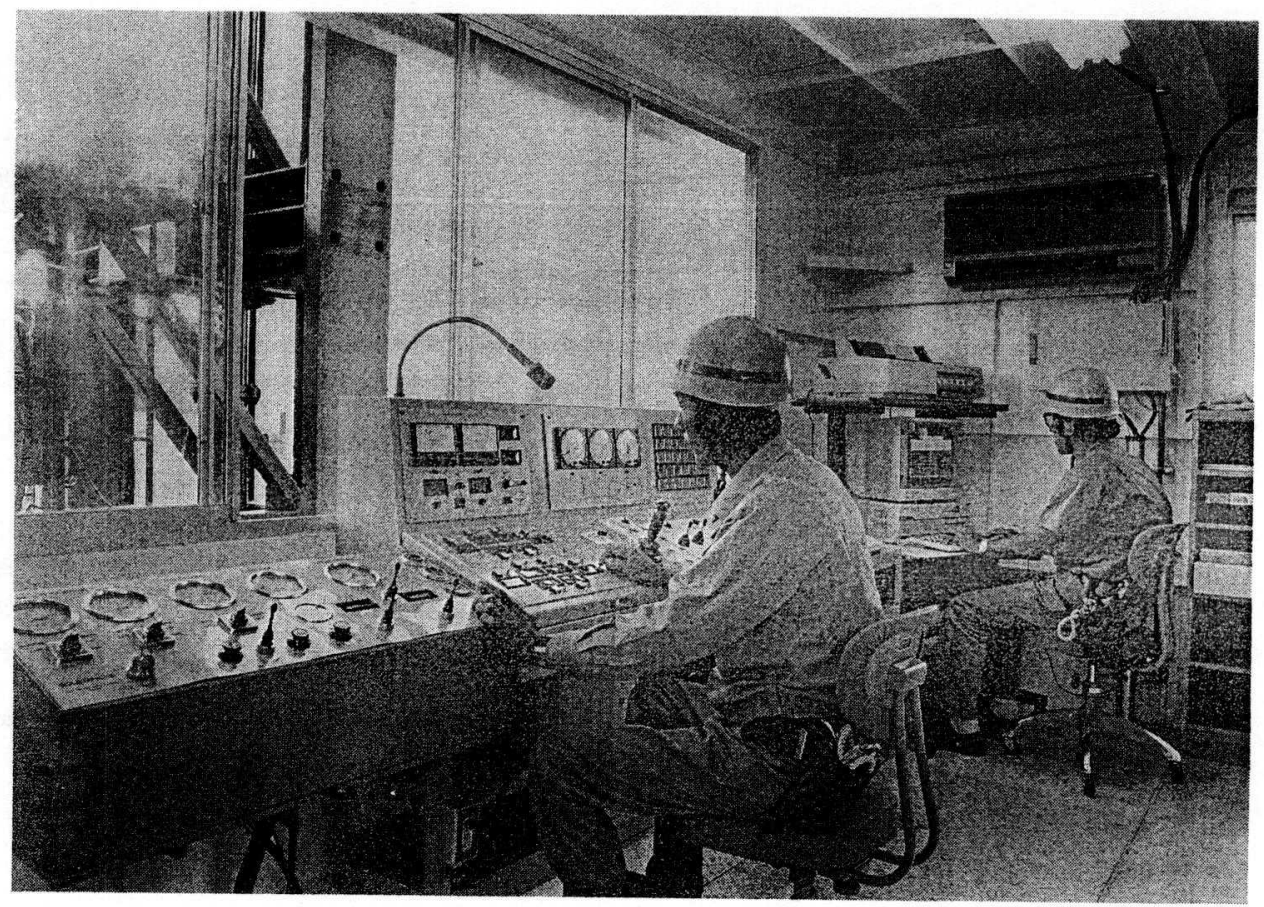

Photo 1. Control room of the excavator
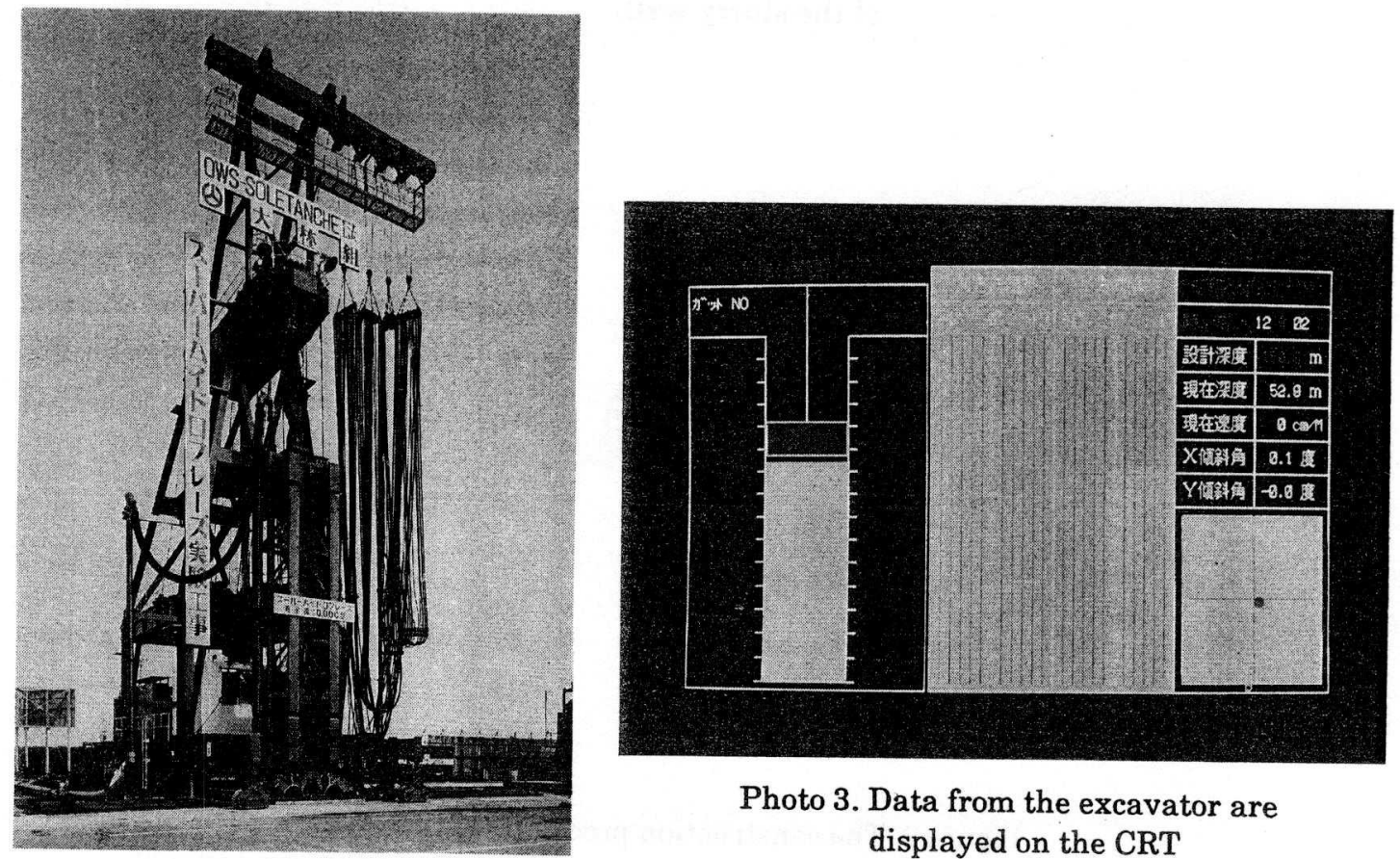

Photo 3. Data from the excavator are displayed on the CRT

Photo 2. Excavator 


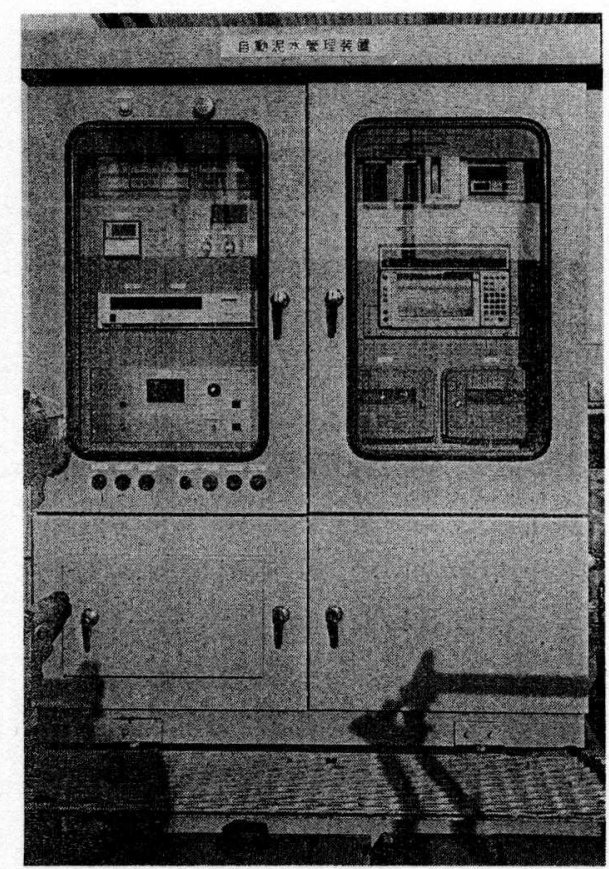

Photo 4. Automatic measurement system of the slurry quality

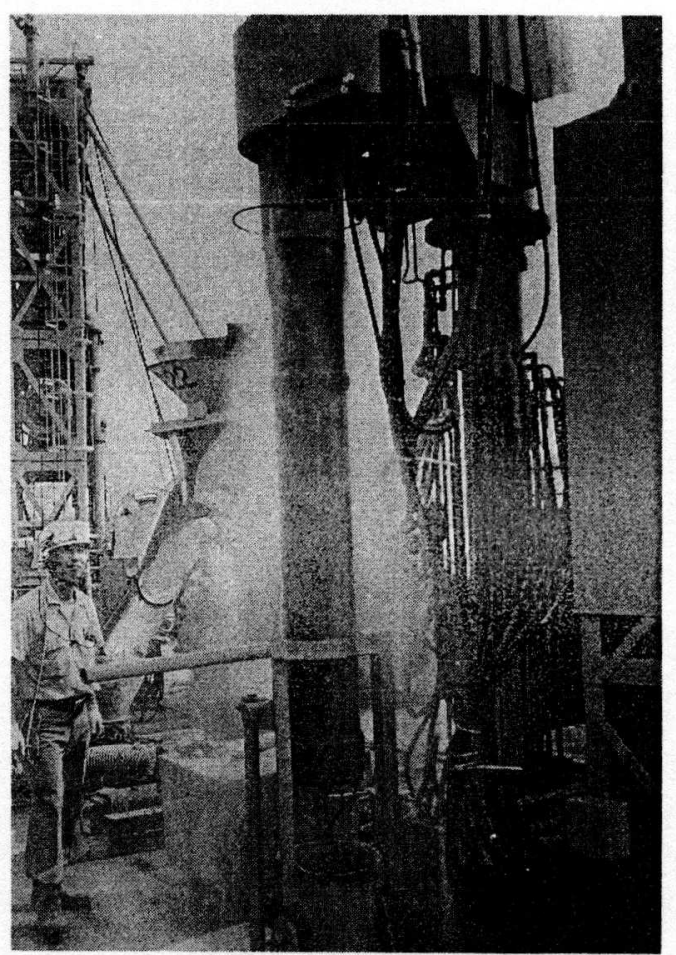

Photo 5. Tremie robot

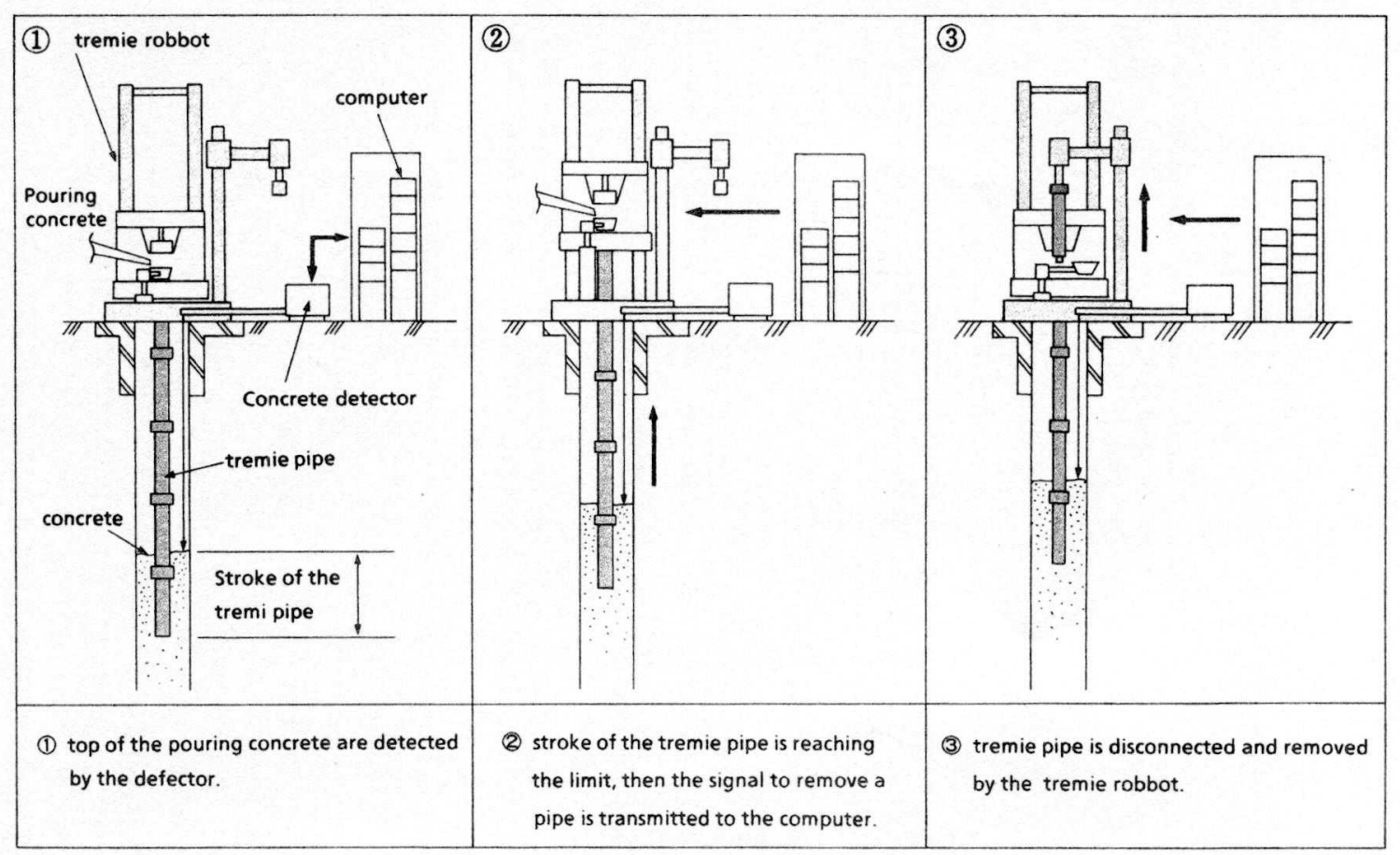

Figure 3. Procedure of the tremie Robot operation 